\title{
Chronic Respiratory Symptoms and Lung Function in a Sample of Agricultural Workers in Skopje Region
}

\author{
Saso Stoleski , Jordan Minov, Jovanka Karadzinska-Bislimovska, Dragan Mijakoski \\ Institute for Occupational Health of Republic of Macedonia - Skopje, WHO Collaborating Center, Ga ${ }^{2}$ len Collaborating \\ Center, Republic of Macedonia
}

\author{
Citation: Stoleski S, Minov M, Karadzinska- \\ Bislimovska J, Mijakoski D. Chronic Respiratory \\ Bislimovska J, Mijakoski D. Chronic Respiratory \\ Symptoms and Lung Function in a Sample of \\ Maced J Med Sci. 2014 Jun 15; 2(2):327-334. \\ haced J J//dx.doi.org/10.3889/oamjms.2014.057 \\ http://dx.doi.org/10.3889/oamjms.2014.057 \\ questionnaire; spirometry; job tasks. \\ "Correspondence: Dr. Saso Stoleski. Institute \\ for Occupational Health of RM - Skopje, Dpt o \\ Cardiorespiratory Functional Diagnostics. 2 \\ Makedonska brigada 43, Skopje 1000, Republi \\ of Macedonia. E-mail: sstoleski@yahoo.com \\ Received: 05-Apr-2014; Revised: 14-Apr- \\ 2014; Accepted: 05-May-2014; Online first: \\ 22-May-2014 \\ Copyright: ๑ 2014 Stoleski et al. This is an \\ open access article distributed under the terms \\ of the Creative Commons Attribution License, \\ which permits unrestricted use, distribution, \\ and reproduction in any medium, provided the \\ original author and source are credited. \\ Competing Interests: The authors have \\ declared that no competing interests exist.
}

\begin{abstract}
OBJECTIVE: To assess the effect of job exposure and its duration on chronic respiratory symptoms and ventilatory capacity among agricultural workers

METHODS: We performed a cross-sectional study including 120 agricultural workers aged 36 to 53 years, compared to an equal number of office workers matched by age, duration of workplace exposure and smoking status. A questionnaire was used to record the chronic respiratory symptoms, detailed job history, specific job activities and tasks performed, and smoking history. Evaluation of examined subjects also included functional lung testing by spirometry.

RESULTS: We found non-significantly higher prevalence of respiratory symptoms in the last 12 months in agricultural workers with significant difference for cough $(P=0.044)$, and wheezing $(P=$ $0.031)$. Mean values of all spirometric parameters were lower in agricultural workers, being significantly different for $\mathrm{MEF}_{50}(P=0.001)$ and $\mathrm{MEF}_{75}(P=0.000)$. Adverse respiratory effects and lung function deterioration were more expressed in agricultural workers with duration of job exposure more than 20 years than in those exposed less than 20 years.
\end{abstract}

CONCLUSION: Our data suggest that workplace exposure in agricultural workers may lead to respiratory impairment which is close related to its duration.

\section{Introduction}

Agriculture is one of the most hazardous sectors in both the developing and industrialized countries. The increasing use of machinery, pesticides and other agrochemicals further aggravates the risks. Agricultural work involves multiple tasks, activities and locations, both on a daily and seasonal basis [1]. On the other hand, agriculture is one of the most common occupations and a relevant income source for the rural population in our country (2).

Exposure to organic dust, pesticides, and other chemical compounds in farming may lead to respiratory diseases and increased annual loss in lung function $[3,4]$, thus respiratory illness is a widely recognized occupational problem among farmers [5].

Epidemiological data indicate that agricultural workers present a higher morbidity and mortality from respiratory disorders than the general population and other occupational groups, despite a lower prevalence of smoking habit [6-8]. Respiratory diseases in farmers may be caused by a wide variety of agents. Organic dusts (grain, straw, hay) usually contain bacteria, moulds, mites and their excreta, as well as animal derivatives (dander, urine, feces), whereas soil activities in the field (plowing, tilling) may expose the workers to inorganic dust, such as silica and silicates. Other hazards include chemical products (pesticides, fertilizers, paints, preservatives, disinfectants), gases and fumes (motor engines, slurry and silage), and infectious agents [8-10].

Regarding the prevalence of chronic respiratory diseases in agricultural workers, exposed to various respiratory hazards, several epidemiological studies have been performed within the last decades. Symptoms of chronic bronchitis have been found to have a much higher frequency in farmers than in non farming population [11] and bronchial obstruction has been found to occur much 
more frequently than expected [12]. Some specific risk factors for respiratory disorders have been demonstrated in farmers, while specific jobs, such as grain handling [13], feeding management [14] and swine attending [15, 16], have been associated with an increased prevalence of respiratory symptoms and increased airway inflammation or bronchial hyperresponsivness. Exposure to endotoxins seems to be a major determinant of the development of airway obstruction in this population [17]. Moreover, farming could be one of the occupations with the highest risks of asthma in a sample of general population [18]. Considering the individual risk factors, prevalence of atopy does not appear to be higher in dairy farmers compared to non farming population [19], unlike the other occupations (like grain handler or animal breeding workers) where it seems to be a relevant risk factor for respiratory disorders [20]. Smoking habit has not been reported as a major risk factor for chronic respiratory symptoms and airway obstruction development in farmers [21] and some authors suggest that the combined effect of farming and age on respiratory functional impairment is synergistic [12].

The aim of this study was to evaluate the prevalence of respiratory symptoms and lung function in a sample of agricultural workers in Skopje region, and to relate them to some risk factors, with particular attention to different job activities performed in the agricultural work.

\section{Subjects and Methods}

Study design and setting

Our team carried out a cross-sectional survey in the Center for Respiratory Functional Diagnostics at the Institute for Occupational Health of R. Macedonia, Skopje - WHO Collaborating Center for Occupational Health and $\mathrm{GA}^{2} \mathrm{LEN}$ Collaborating Center between March 2012 and October 2013.

\section{Subjects}

We have examined 120 subjects, 68 males and 52 females aged 24 to 65 years working as agricultural workers with duration of employment 6 to 45 years (mean duration $18.3 \pm 8.7$ ). By duration of exposure the examined subjects were divided in two subgroups: exposed (dust, vapors, fumes, gases, and pesticides) less or more than 20 years.

The agricultural activities of the participating subjects were: cultivating vegetables $(76 \%)$, planting $(83 \%)$, digging in the fields $(87.6 \%)$, use of mechanized equipment (42.6\%), irrigation $(94.7 \%)$, pesticide use $(67.9 \%)$, cattle breeding $(77.3 \%)$, milking (37.2\%), and stall settling (62.4\%). The exposure of the examined subjects included: inappropriate climatic factors, dust, chemical agents, contact with animals and plants, heavy manual work, loading, unfavorable body positions, repetitive hand movements, and working with sharp tools.

In addition, similar group of 120 office workers (65 males and 55 females) matched to agricultural workers by age, gender, duration of employment, and daily smoking was studied as a control.

The subjects with chronic respiratory disease diagnosed by physician were excluded from the study. All study subjects were informed about the study and their written consent was obtained.

\section{Questionnaire}

All subjects were interviewed by a physician who filled the questionnaire. The questionnaire included questions on work history, respiratory symptoms in the last 12 months, and smoking status of the study subjects.

The work histories of the study subjects were assessed through questions on previous and current job, daily working time, job description, working conditions, specific job activities, as well as protective measures used.

The questionnaire had a special segment dedicated to the presence or absence of different job tasks and activities performed in the agricultural work, as specific occupational risk factors.

Respiratory symptoms in the last 12 months (cough, phlegm, dyspnea, wheezing, and chest tightness) were documented using the European Community for Coal and Steel questionnaire (ECCS87), and the European Community Respiratory Health Survey (ECRHS) questionnaire [22, 23].

Detailed smoking history, accompanying disease, and medication use were also evaluated. Classification of smoking status was done according to the World Health Organization (WHO) guidelines on definitions of smoking status [24].

Daily smoker was defined as a subject who smoked at the time of the survey at least once a day, except on days of religious fasting. In daily smokers lifetime cigarette smoking and daily mean of cigarettes smoked were evaluated. Pack-years smoked (one pack-year denotes one year of smoking 20 cigarettes per day) were calculated according to the actual recommendations [25]. Ex-smoker was defined as a formerly daily smoker, no longer smokes. Passive smoking or exposure to environmental tobacco smoke (ETS) was defined as the exposure of a person to tobacco combustion products from smoking by others [26].

\section{Spirometry}

Spirometry, with measures of forced vital capacity 
(FVC), forced expiratory volume in one second $\left(\mathrm{FEV}_{1}\right), \mathrm{FEV}_{1} / \mathrm{FVC}$ ratio, and maximal expiratory flow at $50 \%, 75 \%$, and $25-75 \%$ of FVC $\left(\mathrm{MEF}_{50}, \mathrm{MEF}_{75}\right.$, and $\mathrm{MEF}_{25-75}$, respectively), was performed in all subjects using spirometer Ganshorn SanoScope LF8 (Ganshorn Medizin Electronic GmbH, Germany) with recording the best result from three measurements of the values of FEV1 within $5 \%$ of each other. The results of spirometry were expressed as percentages of the predicted values according to the European Community for Coal and Steel (ECCS) norms [27].

\section{Statistical analysis}

Statistica for Windows version 7 and Epi info 6 were used for data description and analysis. Continuous variables were expressed as mean values with standard deviation and categorical variables as numbers and percentages. The chi-square test (or Fisher's exact test where appropriate) was used for testing differences in the prevalence of respiratory symptoms, while the comparison of spirometric measurements was performed by independentsamples $T$-test. A $P$-value of less than 0.05 was considered statistically significant. Logistic regression was used to analyze the influence of specific occupational risk factors (job tasks and activities) on the prevalence of respiratory symptoms, taking into account for some confounding factors (age, gender, duration of exposure, and smoking habit). The results are given in terms of odds ratios (ORs) with 95\% confidence intervals (95\% Cls).

\section{Results}

Demographic characteristics of the study subjects were similar in both examined groups (Table 1).

Table 1: Demographics of the study subjects.

\begin{tabular}{lcc}
\hline Variable & $\begin{array}{c}\text { Agricultural } \\
\text { workers } \\
(\mathrm{n}=39)\end{array}$ & $\begin{array}{c}\text { Office workers } \\
(\mathrm{n}=39)\end{array}$ \\
\hline M/F ratio & 1.3 & 1.2 \\
Age range (years) & $24-65$ & $25-65$ \\
Age (years) & $55.9 \pm 6.4$ & $55.3 \pm 6.2$ \\
$\mathrm{BMl}\left(\mathrm{kg} / \mathrm{m}^{2}\right)$ & $24.5 \pm 3.2$ & $24.9 \pm 3.4$ \\
Job exposure (years) & $23.8 \pm 5.9$ & $23.6 \pm 5.7$ \\
Job exposure & $55(45.8 \%)$ & $53(44.2 \%)$ \\
more than 20 years & $28(23.3 \%)$ & $31(25.8 \%)$ \\
Daily smokers & $19.7 \pm 5.4$ & $19.4 \pm 5.2$ \\
Life-time smoking (years) & $14.8 \pm 7.1$ & $15.6 \pm 6.9$ \\
Cigarettes / day & $11.4 \pm 4.1$ & $12.2 \pm 3.9$ \\
Pack-years smoked & $15(12.5 \%)$ & $16(13.3 \%)$ \\
Daily smokers with less than 10 pack- & $7(5.8 \%)$ & $9(7.5 \%)$ \\
years smoked & $19(15.8 \%)$ & $17(14.2 \%)$ \\
Ex-smokers & Passive smokers & \\
\hline Numerical data are expressed as mean valum & with standard deviation; frequencies
\end{tabular}

number and percentage of study subjects with certain variable. BMl: body mass index; $\mathrm{kg}$ : kilogram; m: meter.

Prevalence of respiratory symptoms in the last 12 months was higher in agricultural workers than in controls with statistical significant difference for cough and wheezing (Table 2).
Table 2: Prevalence of respiratory symptoms in the last 12 months in examined groups.

\begin{tabular}{lccc}
\hline $\begin{array}{l}\text { Respiratory symptoms } \\
\text { in the last 12 months }\end{array}$ & $\begin{array}{c}\text { Agricultural workers } \\
(\mathrm{n}=120)\end{array}$ & $\begin{array}{c}\text { Office workers } \\
(\mathrm{n}=120)\end{array}$ & $P$-value* \\
\hline Any respiratory symptom & $32(26.6 \%)$ & $23(19.1 \%)$ & 0.166 \\
Cough & $19(15.8 \%)$ & $9(7.5 \%)$ & 0.044 \\
Phlegm & $10(8.3 \%)$ & $5(4.2 \%)$ & 0.182 \\
Dyspnea & $11(9.2 \%)$ & $4(3.3 \%)$ & 0.061 \\
Wheezing & $14(11.6 \%)$ & $5(4.2 \%)$ & 0.031 \\
Chest tightness & $9(7.5 \%)$ & $6(5.0 \%)$ & 0.423 \\
& & & \\
\hline Data are expressed as number and percentage of study subjects with certain variable.
\end{tabular}

* ${ }^{\text {Data are expressed as number and percentage of study subjects with }}$

Prevalence of respiratory symptoms in the last 12 months was higher in agricultural workers with duration of workplace exposure more than 20 years than in agricultural workers with duration of workplace exposure less than 20 years with significant difference for cough, phlegm and dyspnea (Table 3).

Table 3: Prevalence of respiratory symptoms in the last 12 months in agricultural workers with duration of workplace exposure more and less than 20 years.

\begin{tabular}{lccc}
\hline $\begin{array}{l}\text { Respiratory symptoms } \\
\text { in the last 12 months }\end{array}$ & $\begin{array}{c}\text { Exposed more } \\
\text { than 20 years } \\
(\mathrm{n}=65)\end{array}$ & $\begin{array}{c}\text { Exposed less } \\
\text { than 20 years } \\
(\mathrm{n}=55)\end{array}$ & $P$-value \\
\hline Any respiratory symptom & $21(32.3 \%)$ & $11(20.0 \%)$ & 0.128 \\
Cough & $15(23.1 \%)$ & $4(7.3 \%)$ & 0.018 \\
Phlegm & $9(13.8 \%)$ & $1(1.8 \%)$ & 0.017 \\
Dyspnea & $9(13.8 \%)$ & $2(3.6 \%)$ & 0.050 \\
Wheezing & $10(15.4 \%)$ & $5(9.1 \%)$ & 0.298 \\
Chest tightness & $5(7.7 \%)$ & $4(7.3 \%)$ & 0.930 \\
& & & \\
\hline
\end{tabular}

Data are expressed as number and percentage of study subjects with certain variable. ${ }^{\star}$ Tested by chi-square test or Fisher's exact test where appropriate.

Mean values of spirometric parameters were lower in agricultural workers with statistical difference for $\mathrm{MEF}_{50}$ and $\mathrm{MEF}_{75}$, whereas difference in the mean values of $\mathrm{MEF}_{25-75}$ just missed statistical significance (Table 4).

Table 4: Mean values of spirometric parameters in examined groups.

\begin{tabular}{|c|c|c|c|}
\hline Spirometric parameter & $\begin{array}{c}\text { Agricultural } \\
\text { workers } \\
(\mathrm{n}=120) \\
\end{array}$ & $\begin{array}{l}\text { Office workers } \\
\quad(n=120)\end{array}$ & $P$-value* \\
\hline FVC (\% pred) & $85.4 \pm 8.6$ & $87.3 \pm 8.8$ & 0.092 \\
\hline $\mathrm{FEV}_{1}(\%$ pred) & $82.4 \pm 9.1$ & $84.1 \pm 7.4$ & 0.113 \\
\hline $\mathrm{FEV}_{1} / \mathrm{FVC} \%$ & $73.6 \pm 4.6$ & $74.7 \pm 4.8$ & 0.071 \\
\hline $\mathrm{MEF}_{50}(\%$ pred $)$ & $57.3 \pm 7.5$ & $60.9 \pm 6.8$ & 0.001 \\
\hline $\mathrm{MEF}_{75}$ (\% pred) & $53.7 \pm 6.1$ & $60.3 \pm 7.2$ & 0.000 \\
\hline $\mathrm{MEF}_{25-75}$ (\%pred) & $62.9 \pm 8.2$ & $63.4 \pm 8.1$ & 0.061 \\
\hline
\end{tabular}

Data are expressed as mean value with standard deviation. FVC: forced vital capacity flow at $50 \%, 75 \%$, and $25-75 \%$ of FVC, respectively; $\%$ pred: $\%$ of predicted value. 'Tested by independent-sample $T$-test.

Mean values of spirometric parameters were lower in agricultural workers exposed for more than 20 years than in those exposed less than 20 years with statistical significance for $\mathrm{MEF}_{50}, \mathrm{MEF}_{75}$ and $\mathrm{MEF}_{25-75}$ (Table 5).

Table 5. Mean values of spirometric parameters in agricultural workers with duration of workplace exposure more and less than 20 years.

\begin{tabular}{lccc}
\hline Spirometric parameter & $\begin{array}{c}\text { Exposed more than } \\
20 \text { years } \\
(\mathrm{n}=65)\end{array}$ & $\begin{array}{c}\text { Exposed less } \\
\text { than } 20 \text { years } \\
(\mathrm{n}=55)\end{array}$ & $P$-value* \\
\hline FVC $(\%$ pred) & $82.5 \pm 8.7$ & $84.2 \pm 8.3$ & 0.122 \\
$\mathrm{FEV} 1$ (\% pred) & $80.1 \pm 7.8$ & $81.8 \pm 7.2$ & 0.080 \\
$\mathrm{FEV}_{1} / \mathrm{FVC \%}$ & $72.6 \pm 3.7$ & $73.6 \pm 4.1$ & 0.048 \\
$\mathrm{MEF}_{50}(\%$ pred $)$ & $56.3 \pm 6.4$ & $58.9 \pm 6.2$ & 0.001 \\
$\mathrm{MEF}_{75}(\%$ pred $)$ & $48.6 \pm 7.4$ & $53.9 \pm 7.8$ & 0.000 \\
$\mathrm{MEF}_{25-75}(\%$ pred $)$ & $60.7 \pm 9.7$ & $63.7 \pm 10.1$ & 0.019 \\
\hline Data are expressed as mean value with standard deviation. FVC: forced vital capacity;
\end{tabular}

$\mathrm{FEV}_{1}$ : forced expiratory volume in 1 second; $\mathrm{MEF}_{50}, \mathrm{MEF}_{75}, \mathrm{MEF}_{25.75}$ : maximal expiratory flow at $50 \%, 75 \%$, and $25-75 \%$ of FVC, respectively; $\%$ pred: $\%$ of predicted value. Tested by independent-sample $T$-test. 
Table 6: Respiratory symptoms in relationship with the presence or absence of some specific occupational risk factors (tasks and activities), adjusted for age, gender, and smoking habit.

\begin{tabular}{|c|c|c|c|c|c|c|}
\hline & $\begin{array}{l}\text { Cultivating vegetables } \\
\text { OR }(95 \% \mathrm{Cl})\end{array}$ & $\begin{array}{l}\text { Planting and irrigation } \\
\text { OR }(95 \% \mathrm{Cl})\end{array}$ & $\begin{array}{l}\text { Use of mechanized equipment } \\
\text { OR }(95 \% \mathrm{Cl})\end{array}$ & $\begin{array}{l}\text { Pesticide use } \\
\text { OR }(95 \% \mathrm{Cl}) \\
\end{array}$ & $\begin{array}{l}\text { Animal breeding } \\
\text { OR }(95 \% \mathrm{Cl})\end{array}$ & $\begin{array}{l}\text { Stall settling } \\
\text { OR }(95 \% \mathrm{Cl}) \\
\end{array}$ \\
\hline Any respiratory symptom & $2.5 *(1.2-5.1)$ & $2.2^{*}(1.1-4.6)$ & $1.7(0.8-3.8)$ & $1.9(0.8-4.4)$ & $2.4^{*}(1.1-4.9)$ & $2.3^{*}(1.0-4.7)$ \\
\hline Cough & 2.4 * $(1.1-4.9)$ & 2.2 * $(1.0-4.5)$ & $1.6(0.4-4.7)$ & $1.9(0.7-4.6)$ & $3.1 *(1.1-6.0)$ & $2.8 *(1.3-5.9)$ \\
\hline Phlegm & $2.2 *(1.1-4.3)$ & $2.0 *(1.0-3.9)$ & $1.6(0.7-3.3)$ & $1.8(0.0-3.3)$ & 2.4 * $(1.2-4.7)$ & $1.9 *(0.9-3.8)$ \\
\hline Dyspnoea & $2.1 *(0.9-4.9)$ & $1.9(0.7-4.3)$ & $1.5(0.4-4.9)$ & $1.6(0.5-4.9)$ & $2.0 *(1.1-4.6)$ & $2.0 *(0.9-4.6)$ \\
\hline Wheezing & $3.2 *(1.2-6.3)$ & 2.4 * $(1.2-5.0)$ & $0.8(0.2-2.8)$ & $1.8(0.7-3.9)$ & $2.1 *(1.0-6.1)$ & $1.9(0.8-4.5)$ \\
\hline Chest tightness & $1.5(0.8-3.1)$ & $1.6(0.6-3.4)$ & $0.9(0.3-3.0)$ & $2.0 *(0.9-4.2)$ & $3.2 *(1.2-6.3)$ & $1.4(0.7-2.7)$ \\
\hline
\end{tabular}

An overall number of 6 specific occupational risk factors (agricultural tasks and job activities) were examined, while a control group of workers which did not report any risk factors has been taken as reference. Logistic analysis showed that most chronic respiratory symptoms were significantly associated with some specific jobs related to cultivating vegetables, planting and irrigation, animal breeding, and stall settling, taking into account differences due to age, gender, and smoking habit (Table 6).

\section{Discussion}

Respiratory disease is today an important clinical problem for agricultural workers. Numerous studies, conducted within last few decades, have demonstrated a significantly increased risk of respiratory morbidity and mortality among farm workers, proving the relationship between exposure to respiratory hazards in agriculture and development of chronic respiratory symptoms, and further on development of chronic lung diseases [3].

Our study compared the prevalence of chronic respiratory symptoms and lung function parameters between agricultural and office workers in the region of Skopje, and further examined the relationship between respiratory symptoms and the presence or absence of some specific occupational risk factors (tasks and activities), adjusted for age, gender, and smoking habit.

Data obtained from our recent research concerning agricultural workers showed that their most common activities are: field work, planting vegetables, digging, mechanization and pesticide use, irrigation, cattle breeding, and production of milk and dairy products. During the agricultural process, the exposure of the examined subjects included inappropriate climatic factors, dust, chemical agents and pesticides, contact with animals and plants, heavy manual work, loading, unfavorable body positions, repetitive hand movements, and working with sharp tools.

The prevalence of chronic nasal symptoms among examined groups ranged from $6.8 \%$ to $13.3 \%$, while the prevalence of chronic respiratory symptoms ranged from $16.9 \%$ to $20 \%$, depending on the region. The frequency of lung function impairment registered by spirometry is $23.4 \%$ to $28.8 \%$ [28]. Our further studies in rural areas and among agricultural workers showed that respiratory diseases in the previous 12 months are one of the most frequents ones, with the prevalence of $23,8 \%$ [29].

Many epidemiological and clinical studies referred to a higher prevalence of chronic respiratory symptoms and lung function impairment in agricultural workers compared to other occupations. The frequency of respiratory symptoms depends on the main type of agricultural activity, and mostly on the intensity and duration of organic dust exposure. Research studies showed lower frequency of respiratory symptoms in agricultural workers whose main activity consists of seeds' cultivation, compared to those involved in cattle breeding [30, 31].

The prevalence of chronic respiratory symptoms in our study was $26.6 \%$, and according to the research conducted in Europe their frequency in farmers ranged between $25 \%$ and $35 \%$ [32].

The prevalence of cough with phlegm among agricultural workers in the actual study was $8.3 \%$, which is similar to some of our previous research focused on respiratory effects caused by specific occupational exposure in agricultural workers [33, 34], as well as in the research in Slovenia and Croatia (35). According to the results of the Holland study, the frequency of cough with phlegm in agricultural workers was 2 to $12 \%$ depending on the main agricultural activity, being the highest in those responsible for cattle feeding [32]. The prevalence of cough with phlegm among Finnish farmers was 7.5\% [33], and up to $23 \%$ according to the study in Manitoba, Canada 23\% [37]. According to the Finnish study, performed as a three years follow-up, the prevalence of cough with phlegm was higher, with the annual incidence rate of $2 \%$. The study performed in Denmark included a sample of 834 men from the general population, aged 65 to 84 years, having the highest prevalence for cough with phlegm among the retired agricultural workers [38].

Higher prevalence of other respiratory symptoms in agricultural workers was registered in numerous studies. The research in France showed the highest prevalence of dyspnea among farmers (37\%) and industrial workers (31\%), and the lowest in teachers (15\%) [39]. The results obtained in many studies showed higher frequency of chronic cough in agricultural workers, specially those with the main 
activity in raising sheep [40], pigs or poultry [41]. The study in Poland focused on cultivation of wheat (planting, irrigation, harvesting, and gathering) showed the prevalence of chronic respiratory symptoms of $44.7 \%$, and the highest rates were for chronic cough (26.3\%) and dyspnea (19.7\%) [42]. Many other studies, also confirmed higher prevalence of wheezing among agricultural workers compared to office workers [43].

Chronic respiratory symptoms (cough, phlegm and dyspnea) among agricultural workers in our actual research were significantly related to duration of workplace exposure for more than 20 years, and associated with age over 60 years, exposure to chemical hazards, and smoking habit in males. Many studies reflected on a higher frequency of chronic respiratory symptoms in agricultural workers with longer duration of job exposure [44], while those that investigated the respiratory effects of different types of organic dust, showed significant association between smoking habit and chronic respiratory symptoms [45, 46]. The study among farmers in France showed the synergic effect of occupational exposure and smoking habit, especially for chronic cough and cough with phlegm [47]. The results obtained in a Canadian study showed significant association between cough with phlegm in farmers and the average number of cigarettes per day [48], while another similar study in Canada reported significant association between cough with phlegm, dyspnea and wheezing among agricultural workers, and the duration of smoking [49].

In the actual study we found higher prevalence of overall chronic respiratory symptoms in agricultural workers compared to office controls, with significant difference for cough and wheezing, while statistical significance was just missed for dyspnea.

Similar results were obtained in many studies worldwide, registering also decreased airflow within the small airways without any accompanying respiratory symptoms, which confirmed the fact that limited airflow in the small airways is the earliest sign for respiratory impairment [50-52]. One of our previous research concerning the effect of the organic dust on the frequency and characteristics of exercised induced bronchoconstriction in exposed workers (bakers, textile and agricultural workers) showed significantly lower indices for small airways compared to office controls [53]. The Canadian study dedicated to agricultural workers mainly involved in cereals production in Manitoba, showed non significant difference in the basic spirometric parameters (VC, $\mathrm{FEV}_{1}$ and Tiffeneau index) in comparison with controls, although they were considerably lower in agricultural workers [49].

In the actual research we have registered lower values of spirometric parameters among agricultural workers compared to office controls with statistical significance for mean values of $\mathrm{MEF}_{50}$ and $M \mathrm{MF}_{75}$, whereas difference in the mean values of
$\mathrm{MEF}_{25-75}$ just missed statistical significance. Mixed type of respiratory functional impairment was registered as significant among all examined agricultural workers, whereas ventilatory impairment was associated with age over 60 years, duration of job exposure over 20 years, smoking habit, and exposure to dust and pesticides.

On the other hand, study of Dosman et al. [54], exploring the effect of specific workplace exposure on the frequency of chronic respiratory symptoms and reduction in the lung functional parameters in cereal grain workers in Denmark registered significantly lower values of both basic spirometric and MEF parameters compared to the control group, while their decrease was significantly associated with age and pesticide exposure.

Similar results were described in the study by Corey et al., Enarson et al., and Huy et al. concerning the influence of grain dust on the spirometric parameters in exposed individuals [55-57]. Significantly lower values of VC and $F E V_{1}$ among cattle breeders compared to controls were registered in the study of Dalphin et al., exploring the effects of specific occupational exposure in France [58].

The results obtained in a Danish study dedicated to the exposure-response relationship in pig farmers showed annual decrease in $\mathrm{FEV}_{1}$ of about 12 $\mathrm{mL}$ in exposed workers [52], while another Canadian study that explored the effect of occupational exposure on lung function in cattle breeders registered significant association between the level of decrease in VC, and number of working hours [59].

The research among agricultural workers in Serbia showed annual decrease in $\mathrm{FEV}_{1}$ up to $44 \mathrm{~mL}$ [60]. The Turkish study reported a significant correlation between the level of decrease of FVC and $F E V_{1}$, and the duration of job exposure, dealing with the impact of specific occupational exposure on the lung functional parameters in cow breeders [30]. According to the longitudinal research in Canada among grain workers in barns and silo, decrease in $\mathrm{FEV}_{1}$ was registered after 2.5 to 3 years of work, followed by progressive decrease afterwards [61]. The longitudinal study of Dalphin et al. among farmers in France discovered significant correlation between the decrease in value of Tiffeneau index $\left(\mathrm{FEV}_{1} / \mathrm{FVC} \%\right)$ and both intensity and length of job exposure to organic dust [47].

The already mentioned study among Serbian agricultural workers showed significantly lower values of FVC and FEV 1 compared to the controls with no impact of their smoking status [60]. The synergy between specific occupational exposure and smoking habit present in our actual research was confirmed in many other studies dealing with the respiratory health of agricultural workers. According to the longitudinal study by Tashkin et al. [62], the annual decrease of $\mathrm{FEV}_{1}$ was between 7 and $33 \mathrm{~mL}$, depending on the length and intensity of occupational exposure to aero- 
pollutants and tobacco smoke.

Many epidemiological and clinical studies have demonstrated specific agricultural work-related risk factors for respiratory symptoms, particularly livestock, traditional barn drying of fodder, exposure to endotoxin and ammonia in pig farmers, which were associated with higher prevalence of symptoms of chronic bronchitis [63, 64]. The Italian study by Talini et al [41] recorded a significant role of some specific jobs, such as animal breeding, foddering, cow-shed cleaning and cereal mixing, in increasing the prevalence of some respiratory symptoms, mainly chronic cough and phlegm. These working activities were strongly related to endotoxins and organic dust exposure, thus suggesting the possible role of those agents in the etiology of chronic bronchitis. According to this Italian study out of several jobs performed in the agricultural setting, those related to animal breeding were significantly associated with respiratory symptoms, and seemed to be the major risk for respiratory disorders in farmers. Our actual research showed significant association between most of the chronic respiratory symptoms and cultivating vegetables, planting and irrigation, as well as animal breeding and stall settling.

The present study has some limitations. Namely, relatively small number of the subjects in the study groups may be a major limitation, having a certain implications on the data obtained and its interpretation. Also, there is a lack of skin prick testing to common and workplace allergens, to closely document the relationship between sensitization to workplace allergens with respiratory symptoms and lung function parameters. As a conclusion, within the actual study focused on assessment of adverse respiratory effects in agricultural workers we found higher prevalence of respiratory symptoms in the last 12 months with significant difference for cough and wheezing, as well as significantly lower values of two parameters of forced expiratory flow MEF $_{50}$ and $\mathrm{MEF}_{75}$ ), in agricultural workers than in controls. Respiratory impairment was closely related to the duration of workplace exposure, while chronic respiratory symptoms had a significant association with some specific agricultural tasks and activities.

The results that were obtained in the present study confirm the fact that specific occupational exposure in agricultural workers can lead to certain impairments of their respiratory health, which are generally preventable.

\section{References}

1. International Labour Office (ILO). Safety and health in agriculture. Safework. Program on safety, health and the environment. Available at: www.ilo.org/safework. Accessed 15 March 2014.

2. State Statistical Office. Census of agriculture - 2007, 2007.

3. Schenker MB, Christiani D, Cormier $Y$, et al. Respiratory health hazard in agriculture. Am J Respir Crit Care Med. 1998;158:1-76.
4. Linaker C, Smedley J. Respiratory illness in agricultural workers. Occup Med (Lond). 2002;52:451-459.

5. Omland, O. Exposure and respiratory health in farming in temperate zones-a review of the literature. Ann Agric Environ Med. 2002; 9:119-136.

6. Heller RF, Kelson MC. Respiratory disease mortality in agricultural workers in eight member countries of the European Community. Int J Epidemiol. 1982; 11: 170- 174.

7. Toren K, Horte L-G, Jarvholm B. Occupation and smoking adjusted mortality due to asthma among Swedish men. $\mathrm{Br} \mathrm{J}$ Ind Med. 1991; 48: 323-326.

8. Linaker C, Smedley J. Respiratory illness in agricultural workers. Occup Med. 2002; 52: 451-459.

9. Schenker M. Exposures and health effects from inorganic agricultural dusts. Environ Health Perspect. 2000; 108 (Suppl 4): 661-664.

10. Omland $\mathrm{O}$. Exposure and respiratory health in farming in temperate zones - a review of the literature. Ann Agric Environ Med. 2002; 9: 119-136.

11. Husman K, Koskenvuo M, Kaprio J, Terho Eo, Vohlohnen I. Role of environment in the development of chronic bronchitis. Eur $\mathrm{J}$ Respir Dis. 1987; 71 (Suppl. 152): 57-63.

12. Dalphin JC, Bildstein F, Pernet D, Dubiez A, Depierre A Prevalence of chronic bronchitis and respiratory function in a group of dairy farmers in the French Doubs province. Chest. 1989; 95: 1244-1247.

13. Chan Yeung M, Schulzer M, MacLean L, Dorken E, Grzybowski $\mathrm{S}$. Epidemiologic health survey of grain elevator workers in British Columbia. Am Rev Respir Dis. 1980; 121: 329-338.

14. Radon K, Opravil U, Hartung J, Szadkowski D, Nowak D. Workrelated respiratory disorders and farming characteristics among cattle farmers in Northern Germany. Am J Ind Med. 1999; 36 (4): 444-449.

15. Larsson K, Eklund A, Isaksson BM, Malmberg P. Swine dust causes intense airway inflammation in healthy subjects. Am J Respir Crit Care Med. 1994; 150: 973-977.

16. Preller L, Heederik D, Boleij JS, Vogelzang PFJ, Tielen MJM. Lung function and chronic respiratory symptoms of pig farmers: focus on exposure to endotoxins and ammonia and use of disinfectants. Occup Environ Med. 1995; 52: 654-660.

17. Rylander $R$, Jacobs RR, eds. Endotoxins in the environment: criteria document. Int J Occup Environ Health. 1997; 3: S1-S48.

18. Kogevinas $M$, Antó JM, Sunyer J, Tobias $A$, Kromhout $H$, Burney P. Occupational asthma in Europe and other industrialised areas: a population-based study. European Community Respiratory Health Survey Study Group. Lancet. 1999; 353 (9166): 1750-4.

19. Malmberg $P$. Health effects of organic dust exposure in dairy farmers. Am J Ind Med. 1990; 17: 7-15.

20. Chan-Yeung M, Enarson D, Kennedy SM. State of the art: impact of grain dust on respiratiory health. Am Rev Respir Dis. 1990; 145: 476-487.

21. Babbott FL, Gump BW, Sylwester DL, MacPherson BV, Cinthia Holly R. Respiratory symptoms and lung function in a sample of Vermont dairy men and industrial workers. Am J Public Health. 1980; 70: 241-245.

22. Minette A. Questionnaire of the European Community for Coal and Steel (ECSC) on respiratory symptoms. 1987 - Updating of the 1962 and 1967 questionnaires for studying chronic bronchitis and emphysema. Eur Respir J. 1989;2:165- 177.

23. European Community Respiratory Health Survey. Variations in the prevalence of respiratory symptoms, self-reported asthma attacks, and use of asthma medication in the European Respiratory Health Survey (ECRHS). Eur Respir J. 1996;9:687-695. 
24. World Health Organization. Guidelines for controlling and monitoring the tobacco epidemic. Geneva: WHO, 1998.

25. Smoking Pack-Years. Available from: http://smokingpackyears.cm/calculate. Accessed 10 March 2014.

26. US Department of Health and Human Services. The health consequences of smoking: chronic obstructive pulmonary disease. A report of the Surgeon General. US Department of Health and Human Services, Public Health Service, Office of the Assistant for Health, Office of Smoking and Health. DHHS Publication No. 84-50 205,1984 .

27. Quajner $\mathrm{PhH}$, ed. Standardization of Lung Function Tests 1993 Update. Report Working Party for the European Community for Steel and Coal. Official Statement of the European Rrespiratory Society. Eur Rrespir J. 1993;16(I):1-100.

28. Karadzinska-Bislimovska J, Minov J, Stoleski S, Mijakoski D, Risteska-Kuc S, Milkovska S. Environmental and occupational health risks among agricultural workers living in rural community near petroleum refinery and highway in Skopje region. Arh Hig Rada Toksikol. 2010; 61:415-424.

29. Stoleski S, Karadzinska-Bislimovska J, Minov J, Mijakoski D. Current needs and future development in Macedonian rural health policy. International forum on Occupational Health and Safety: Policies, Profiles and Services. Espoo: Finland, 2011: 61.

30. Kuchuk A, Basanets A, Louhelainen K. Bronchopulmonary pathology in workers exposed to organic fodder dust. Ann Agric Environ Med. 2000;7:17-23.

31. Chen Y, Horne S. L., McDuffie H.H, Dosman J.A. Combined effect of grain farming and smoking on lung function and the prevalence of chronic bronchitis. Int J Epidemiol.1991; 20(2):416423.

32. Bongers $P$, Houthuijs $D$, Remijn $B$, Brouwer $R$, Biersteker $K$ Lung functions and respiratory symptoms in pig farmers. $\mathrm{Br} \mathrm{J}$ Ind Med. 1987;44:819-823.

33. Karadzinska-Bislimovska J, Minov J, Stoleski S, Mijakoski D, Risteska-Kuc S. Respiratory symptoms, atopic status and lung function tests in agricultural workers. Allergy. 2007; 62 (83): 283

34. Trajceva L, Minov J, Karadzinska-Bislimovska J, Risteska-Kuc $\mathrm{S}$, Stoleski S, Mijakoski D. Nasal symptoms in agricultural and administration workers: association with respiratory symptoms. In Book of abstracts. 4th Congress of Macedonian Respiratory Association with International Participation, Ohrid, 2008: 191.

35. Milosevic M. The prevalence of chronic bronchitis in agricultural workers of Slavonia. Am J Ind Med. 1986; 10:319-322.

36. Terho EO. Work-related respiratory disorders among Finnish farmers. Am J Ind Med. 1990;18:269-272.

37. Warren CPW, Manfreda J. Respiratory symptoms in Manitoba farmers: association with grain and hay handling. CMA Journal. 1980;122:1259-1264

38. Heederik D, Pouwels $H$, Kromhout $H$, Kromhout D. Chronic nonspecific lung disease and occupational exposures estimated by means of a job exposure matrix: the Zutphen study. Inr J Epidemiol. 1989;18:382-389

39. Kauffmann F, Drouet D, Lellouch J, Brille D. Occupational exposure and 12 year spirometric changes among Paris area workers. Br. .l. tnd. Med. 1982;39:221-232.

40. Magarolas R, Monsó E, Aguilar X, Radon K, Nowak D, Martínez $\mathrm{C}$, Morera J. Prevalence and risk factors of respiratory symptoms in farmers; comment. Med Clin (Barc). 2000;114(18):685-9.

41. Talini D, Monteverdi A, Carrara M, Paggiaro PL. Risk factors for chronic respiratory disorders in a sample of farmers in middle Italy. Monaldi Arch Chest Dis. 2003; 59: 1, 52-55.

42. Skórska C, Mackiewicz B, Dutkiewicz J, Krysińska-Traczyk E Milanowski J, Feltovich H, Lange J, Thorne P. Effects of exposure to grain dust in Polish farmers: work-related symptoms and immunologic response to microbial antigens associated with dust.
Ann Agric Environ Med. 1998;5(2):147-53.

43. Chan-Yeung M, Dimich-Ward H, Enarson D.A, Kennedy SM. Five cross-sectional studies of grain elevator workers. Am J Epidemiol. 1992;136:1269-1279.

44. Zock JP, Sunyer J, Kogevinas M, Kromhout H, Burney P, Anto $\mathrm{JM}$. Occupation, chronic bronchitis, and lung function in young adults. An international study. Am J Respir Crit Care Med. 2001; 163: $1572-1577$

45. Zuskin E, Mustajbegovic J, Schachter EN, Doko-Jelinic J. Respiratory function of textile workers employed in dyeing cotton and wool fibers. Am J Ind Med. 1997; 31: 344-352.

46. Ulvestad B, Bakke B, Eduard W, Kongerud J, Lund MB. Cumulative exposure to dust causes accelerated decline in lung function in tunnel workers. Occup Environ Med. 2001; 58: 663-669.

47. Dalphin JC, Dubiez A, Monnet E, Gora D, Westeel V, Pernet D, Polio JC, Gibey R, Laplante JJ, Depierre A. Prevalence of asthma and respiratory symptoms in dairy farmers in the French province of the Doubs. Am J Respir Crit Care Med. 1998;158(5 Pt 1):1493-8.

48. Chen Y, Horne SL, McDuffie HH, Dosman JA. Combined effect of grain farming and smoking on lung function and the prevalence of chronic bronchitis. Monaldi Arch Chest Dis. 2003;59(1):52-5.

49. Warren CP, Manfreda J. Respiratory symptoms in Manitoba farmers: association with grain and hay handling. Can Med Assoc J. 1980;122(11):1259-1264

50. Holness D. L, O'Blenis E.L, Sass-Kortsak A, Pilger C, Nethercott J.R. Respiratory effects and dust exposures in hog confinement farming. Am J Ind Med. 1987;11:571-580.

51. Choudat D, Goehen M, Korobaeff M, Boulet A, Dewitte J.D, Martin M.H. Respiratory symptoms and bronchial reactivity among pig and dairy farmers. Scand J Work Environ Health. 1994;20:4854 .

52. Iversen $\mathrm{M}$, Pedersen $\mathrm{B}$. Relation between respiratory symptoms, type of farming, and lung function disorders in farmers. Thorax. 1990;45:919-923.

53. Minov J, Karadzinska-Bislimovska J, Vasilevska K, RisteskaKuc S, Stoleski S. Exercise-induced bronchoconstriction in textile and agricultural workers and in bakers. Arh Hig Rada Toksikol. 2006; 57: 379-386

54. Dosman J. A, Graham B.L, Hall D, Van Loon P, Bhasin P, Froh F. Respiratory symptoms and pulmonary function in farmers. $J$ Occup Med. 1987;29:38-42.

55. Huy T, De Schipper K, Chan-Yeung M, Kennedy S.M. Grain dust and lung function: exposure response relationships. Am Rev Respir Dis. 1991;144:1314-1321.

56. Corey P, Hutcheon M, Broder I, Mintz S. Grain elevator workers show work-related pulmonary function changes and doseeffect relationshios with dust exposure. $\mathrm{Br} \mathrm{J}$ Ind Med. 1981;39:330-337.

57. Enarson DA, Vedal S, Chan-Yeung M. Rapid decline in FEV in grain handlers. Am Rev Respir Dis. 1985;132:814-817

58. Dalphin JCH, Pernet D, Dubiez A, Debieuvre D, Allemand H, Depierre A. Etiologic factors of chronic bronchitis in dairy farmers, case control study in the Doubs region of France. Chest. 1993;103:417-421.

59. Zejda JE, Gomez S, Hurst T.S, Barber E.M, Rhodes C, McDuffie H, Dosman JA. Respiratory health of swine producers working in livestock confinement buildings. In McDuffie $\mathrm{HH}$, Dosman JA, Semchuck KM, Olenchock SA, Senthilselvan A (eds). Supplement to Agricultural Health and Safety: Workplace, Environment, Sustainability. Center for Agricultural Medicine, University of Saskatchewan. Saskatoon. 1994;7-16.

60. Djuricić S, Minić P, Radovanović S, Babić DD, Gavrilov M. Basic spirometry measurements in workers on pig farmers. Srp Arh Celok Lek. 2004;132(3-4):85-91.

61. Chan-Yeung M, Dimich-Ward H, Enarson DA, Kennedy SM. 
Five cross-sectional studies of grain elevator workers. Am J Epidemiol. 1992;136:1269-1279.

62. Tashkin PD, Detels R, Simmons M, Liu H, Coulson AH, Sayre J, Rokaw S. The UCLA population studies of chronic obstructiverespiratory disease: XI Impact of air pollution and smoking habit on annual change in forced expiratory volume in one second. Am J Respir Crit Care Med. 1994; 149: 1209-1217.

63. Schenker M, Ferguson T, Gamsky T. Respiratory risks associated with agriculture. Occup Med. 1991; 6: 415-428.

64. Dalphin JC, Polio JC, Pernet D, Maheu MF, Toson B, Dubiez A, Monnet E, Laplante JJ, Depierre A. Influence of barn drying of fodder on respiratory symptoms and function in dairy farmers of the Doubs region of France. Thorax. 1994; 49:50-53. 